\title{
Modern Remote Training Programs For Early Career Psychiatrists - The Role Of Young Scientists In The Learning Process
}

\author{
E. Chumakov ${ }^{1,2}$, I. Fedotov ${ }^{3}$, N. Petrova ${ }^{1}$
}

\begin{abstract}
${ }^{1}$ Saint-Petersburg State University, Department of Psychiatry and Addictions, Saint-Petersburg, Russia ${ }^{2}$ St.-Petersburg Psychiatric Hospital No 1 named after P.P. Kaschenko, Saint-Petersburg, Russia

${ }^{3}$ Ryazan State Medical University, Psychiatry Department, Ryazan, Russia.
\end{abstract}

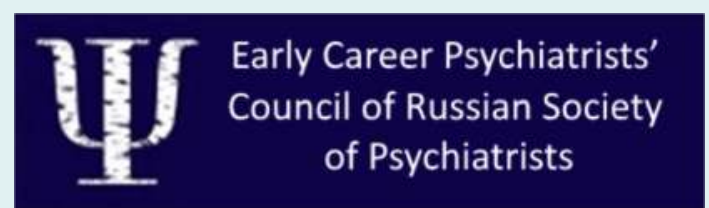

Objectives. The possibility of distance learning is becoming an increasingly important part of the training of specialists around the world and is particularly in demand among early career scientists and specialists. In this regard, the ECPs' Council of the Russian Society of Psychiatrists conducts its own remote training projects aimed primarily at the needs and difficulties of young professionals.

Background and Aims. Despite the fact that we hold offline educational seminars and conferences the development of remote educational projects has become important for us, as there are 11 time zones in Russia.

Materials and Methods. Since 2016 ECPs' Council Section on web-resources conducted a series of free of charge webinars on psychopharmacotherapy, fundamental neuroscience, translational psychiatry, psychotherapy and others (in total 44 webinars with 13758 views) (Table 1).

\begin{tabular}{|l|c|c|}
\hline \multicolumn{1}{|c|}{ Series of webinars } & $\begin{array}{c}\text { Number of } \\
\text { webinars in the } \\
\text { series }\end{array}$ & $\begin{array}{c}\text { Total number of } \\
\text { webinars views in } \\
\text { the series }\end{array}$ \\
\hline $\begin{array}{l}\text { Modern } \\
\text { Psychopharmacology }\end{array}$ & 10 & 3,406 \\
\hline $\begin{array}{l}\text { Fundamental } \\
\text { Neuroscience and } \\
\text { Translational Psychiatry }\end{array}$ & 10 & 2,038 \\
\hline $\begin{array}{l}\text { General and Particular } \\
\text { Issues of Psychotherapy }\end{array}$ & 16 & 6,250 \\
\hline $\begin{array}{l}\text { Webinars on personal } \\
\text { requests of young } \\
\text { scientists }\end{array}$ & 8 & 2,064 \\
\hline
\end{tabular}

Table 1. Series of webinars conducting by the Russian ECPC in 2016-2019

Results. This project was implemented with the support of the Russian Society of Psychiatrists Chair of the commission for work with young scientists and specialists. The first series of webinars were conducted by young scientists who defended the $\mathrm{PhD}$ thesis on the most relevant topics of psychiatry in recent years, but with the increased demand for our webinars, our lecturers are already professors and opinion leaders in Russia.
The peculiarity of our project is that the training process is not only technically organized by young specialists, but also the training itself is conducted by young scientists. They usually give lectures on their scientific interests and $\mathrm{PhD}$ theses topics. We have up to 1370 views of the records of each webinar. Statistics show that interest in our project remains high throughout the year 2018-2019 (Figure 1).

Topics of webinars are taken from the requests of the young scientists. Our webinars are available for free on our website http://smu.psychiatr.ru// (Figure 2 ), YouTube channel, and in our official groups in social networks (for example Facebook https://www.facebook.com/groups/ecpcru).

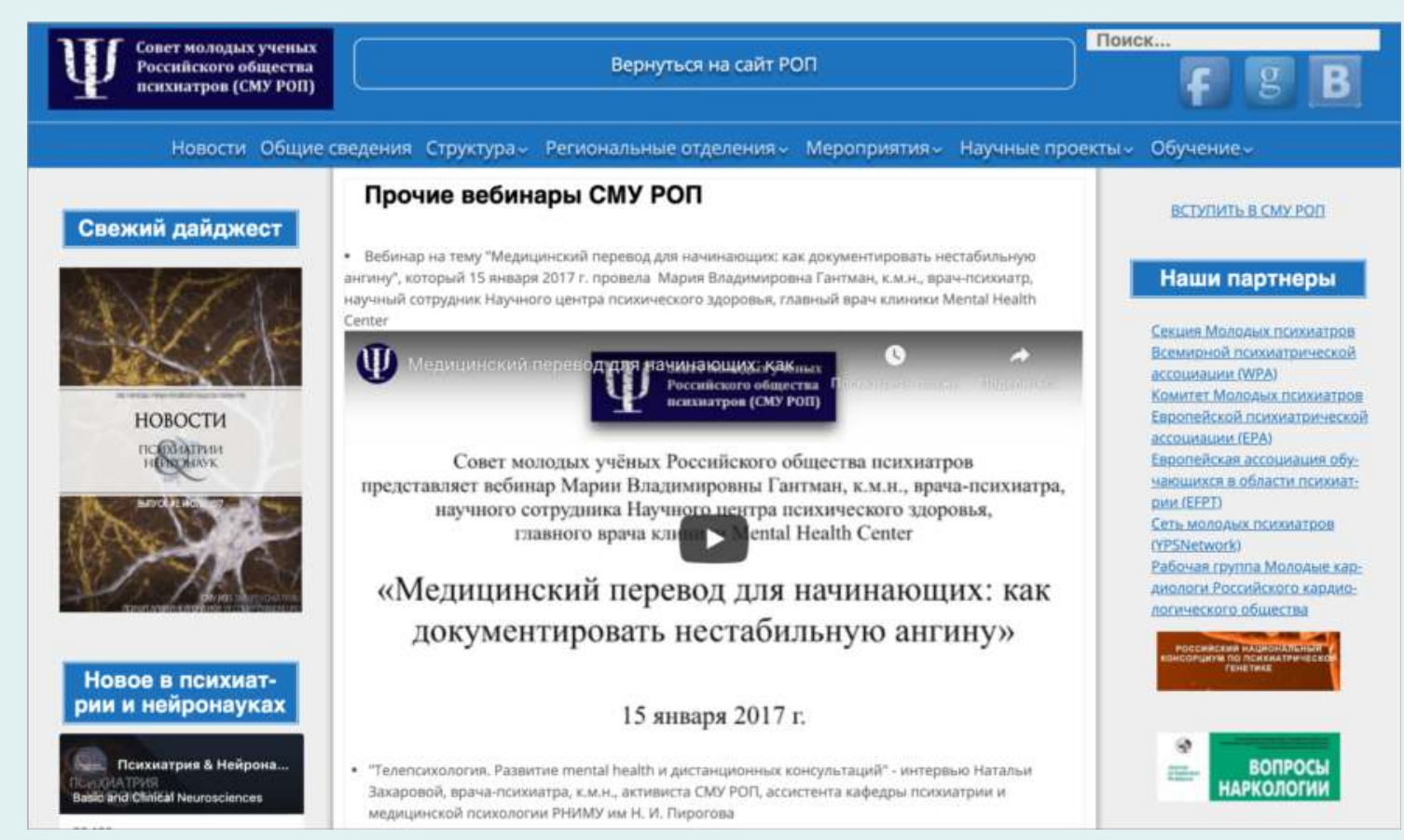

Figure 2. Screenshot of the official ECPs' Council of the Russian Society of Psychiatrists website with one of the webinars

We plan to continue this project. Currently, preparations are under way for the next series of webinars on the rehabilitation of patients with mental disorders and clinical guidelines in psychiatry.

Our goal is to include our webinars to the system of Continuous Medical Education in Russia with official aprovement.

Conclusions. Our experience shows that webinars are a convenient and in-demand form of training, especially in large countries with the complexity of meeting at face-to-face events. The development of this project is included in the priorities of the ECPs' Council of the Russian Society of Psychiatrists.

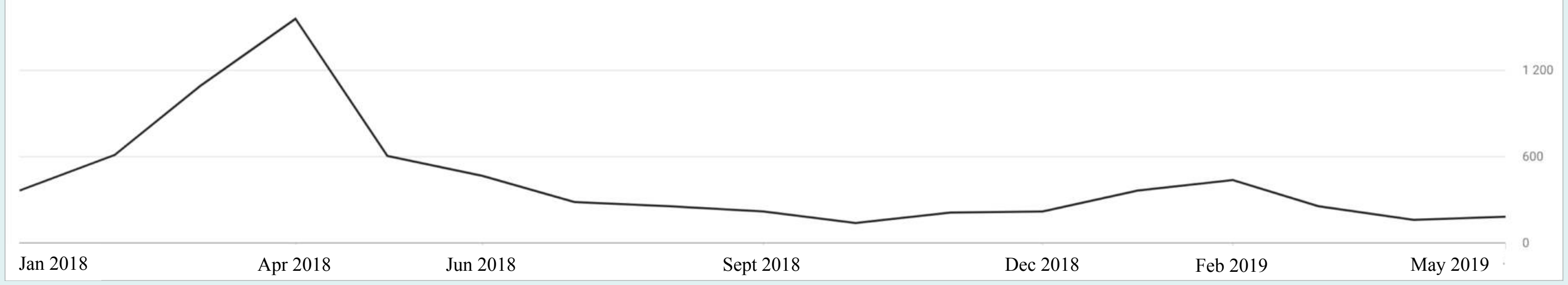

Figure 1. Statistics on the webinar's records number of views in 2018-2019

*The authors report no conflicts of interest and received no financial support directly related to the research, authorship, and/or publication of this target article. 